\title{
A Study to Assess the Internet Addiction among Adolescents Studying in Dyal Singh Government Senior Secondary School, Mirjajan, District Gurdaspur, Punjab
}

\author{
Ramandeep Kaur Bajwa', Sushil Kumar Maheshwari²
}

${ }^{1}$ Department of Mental Health Nursing, Nursing Officer, Government Rajindra Hospital, Patiala, Punjab, India, ${ }^{2}$ Department of Mental Health Nursing, University College of Nursing, Faridkot, Punjab, India

\section{Abstract}

Aim: The aim of the study was to assess the level of internet addiction among adolescents and to find out the association between the level IA among adolescents studying in Government Senior Secondary School, Mirjajan, and their selected demographic variables and to distribute pamphlets related to conscious use of internet.

Methodology: The descriptive study was conducted in Dyal Singh Government Smart Senior Secondary School. The study accessible population was adolescents selected by simple random sampling technique. Data were collected from adolescents by modified Internet Addiction Test. Data were analyzed by descriptive and inferential statistics through bar and pie diagrams.

Results: It shows that $55.0 \%$ of adolescents were having moderate internet addiction, $21.7 \%$ of adolescents were having mild internet addiction, $16.7 \%$ of them were normal users, and only $6.7 \%$ of them were having severe internet addiction. Chi-square value between level of internet addiction and sociodemographic variables including occupation of mother with $P=0.001$, occupation of father with $P=0.780$, education of mother with $P=0.052$, and education of father with $P=0.003$ was found to be statistically significant at the level of 0.05 .

Conclusion: The findings of the present study revealed that majority of the adolescents were having moderate internet addiction and there was a significant association between the level of internet addiction with occupation and education of parents.

Keywords: Adolescents, Descriptive study, Internet Addiction

\section{INTRODUCTION}

Adolescence can be defined as the period between puberty and adulthood, usually between the ages of 11 and 18 years. Events during this period greatly influence a person's development and can determine their attitudes and behavior in later life. Adolescence can be divided into three substages: Early, middle, and late ${ }^{[1]}$ One of the most important functions of adolescence is to find one's own identity and view of life, without inner conflict and the need to always act within

\section{Access this article online}

Website: http://innovationalpublishers.com/Journal/ijnmi

ISSN No: 2656-4656

DOI: $10.31690 /$ ijnmi.2020.v05i02.002 acceptable moral standards, abide by parental authority, or meet peer expectations ${ }^{[2]}$ Because teenagers are often in conflict with authority and cultural and moral norms of society, certain developmental effects can trigger a series of defense mechanisms. ${ }^{[1]}$

In the past few years, smart phones have become an integral part of our lives. The number of mobile cellular subscription is constantly increasing every year. Around 26 published survey reports suggest than $50 \%$ of teens and $27 \%$ of parents feel that they are addicted to mobiles. The recent studies also reported the increase number of mobile phone dependence, this could increase internet addiction. Since the mid-1990s, internet addiction has been proposed as a new type of addiction and mental health problem, similar to alcoholism and compulsive gambling. ${ }^{[3]}$

This is an open-access journal, and articles are distributed under the terms of the Creative Commons Attribution Noncommercial Share Alike 4.0 License, which allows others to remix, tweak, and build upon the work non-commercially, as long as appropriate credit is given and the new creations are licensed under the identical terms 
During adolescence, there is an increased risk of emotional crises, often accompanied by mood changes and periods of anxiety and depressive behavior, which adolescents attempt to fight through withdrawal, avoidance of any extensive social contact, aggressive reactions, and addictive behavior. ${ }^{[4,5]}$ Adolescents are exceptionally vulnerable and receptive during this period and can become drawn to the internet as a form of release. Overtime, this can lead to an addiction. Adolescents are especially attracted to new technological methods of communication, which offer interaction with others and at the same time provide anonymity, impression of belonging to a community, and a sense of social acceptability. ${ }^{[5]}$

The internet as a global network connects millions of people throughout the world and enables users to exchange information, which remains available at any time and any place. ${ }^{[6]}$

A descriptive study was conducted to assess the level of IA and its impact among high school students in Mangalore. A conceptual framework was based on Roy's Adaptation Model. The tool consisted of a baseline pro forma, a modified form of IA test and a structured questionnaire developed during the study. Those tools were employed to assess the level of IA and its impact among adolescents of English medium high schools. The reliability of the tool was determined using a split half technique. The study revealed that majority (70.5\%) of the adolescents were normal users, $23 \%$ had a mild addiction, $6 \%$ had a moderate addiction, and $0.5 \%$ had a severe addiction. The majority ( $73 \%$ ) of samples had a mild impact, $16.5 \%$ had a moderate impact, and $10.5 \%$ had no impact. Some of their demographic variables such as age, class, and occupation of fathers have significant associations with both IA and impact of IA..$^{[7]}$

As the internet increasingly becomes part of our lives, internet addiction disorder has received much attention. A high rate of comorbid mental disorders has also been reported, especially anxiety symptoms and social impairment. ${ }^{[8]}$ As every innovation and technology has pros and cons, mobile use also has advantages and disadvantages. Ignorance of the disadvantages among students has led to a long way health hazards. Hence, the investigator feels that there is a need to assess the internet addiction among adolescents and to educate them to minimize or prevent the impact on one's health appeared. The internet was originally designed to facilitate communication and research activities. However, the dramatic increase in the use of the internet in recent years has led to pathological use.

\section{Research Methodology}

To accomplish the objectives of the study, a quantitative research approach was adopted. This approach was appropriate for the study because it aims to assess the level of internet addiction among adolescents studying at Government Senior Secondary School, Mirjajan, District Gurdaspur, Punjab. Adolescents between the age group of 14 and 18 years studying in the $10^{\text {th }}, 11^{\text {th }}$, and $12^{\text {th }}$ standard in Government Senior Secondary School, Mirjajan, district Gurdaspur, Punjab. Research variable was internet addiction. Sample is a small portion of the population selected for observation and analysis. Sixty samples were used in this study.

Sampling technique is a procedure which the researcher adopts in selecting the sample for the study. Simple random sampling technique (lottery method) was used to collect the samples. The roll numbers of the students were written on the slips and after preparing all the slips, they were folded in similar manner to hide the material written on the slips. In the presence of cosupervisor, the folded slips were put in the container. Investigator shuffled the container and then picked the slip and then again the container was shuffled before picking the next slip till the desired students from the class were selected without replacing the slips. The study included adolescents who are as follows:

- Between the age group of 14 and 18 years.

- Available at the time of data collection.

The study excluded adolescents who are as follows:

- Not between the age group of 14 and 18 years.

- Not willing to participate.

The main concern of the study was to assess the internet addiction among adolescents. The tool related to the assessment of level of internet addiction after extensive review of literature, consultation, and discussion with experts of psychiatry. Part A: It includes items for obtaining personal information's of subjects, that is, gender, age, class, type of family, number of siblings, education of father, education of mother, occupation of father, occupation of mother, and mode of internet access. Part B: A modified form of IAT by Kimberley and Young used to assess the level of IA. It consists of the 20-item questionnaire based on the 5-point Likert scale.

Permission was taken from concerned authority of selected school to conduct research study. A written consent was taken from students. Anonymity and confidentiality of the information were maintained during and after data collection.

\section{Data Collection Procedure}

Data collection was done in February 2019 Dyal Singh Government Senior Secondary School, Mirjajan, district Gurdaspur, Punjab. Before the data collection, permission was be taken from the principal of school for conducting the study. The aim and nature of the study was explained to the principal. Students were explained about objective, activities, and duration of their involvement. Written informed consent was taken from the subjects. The data were collected from February 5, 2019, to February 7, 2019. The responses from the students were collected by filling questionnaire. The Internet Addiction Test was used to assess the level of internet addiction among adolescents. The 
investigator made sure that the students were comfortable to fill up the questionnaire. Instructions were given regarding filling of questionnaire and were asked to tick against each statement. They were encouraged to ask any doubt if they had and query raised were clarified. And then, they were also assured that their responses will be kept confidential and used for research purpose only. Adolescents have full authority to participate in research and withdraw from research at any time. Average time taken to fill the questionnaire ranged from 25 to $30 \mathrm{~min}$.

Analysis of the data was done in accordance with the objectives using the descriptive and inferential statistics and findings were presented in the form of tables and figures. The final data transformed to SPSS 15.0 evaluation version and analyzed using appropriate descriptive and inferential statistics.

\section{RESULTS}

Table 1 depicted sociodemographic profile of adolescents. Around $28.3 \%$ of adolescents were in the age of 15 years, $23.3 \%$ of adolescents were in the 16 and 18 years, and $16.7 \%$ of adolescents were in the age group of 14 years and rest $8.3 \%$ of adolescents were in the age group of 17 years. Out of 60 adolescents, $70 \%$ were male and $30 \%$ were female.

Equal proportion, that is, $33.3 \%$ of adolescents were from the $10^{\text {th }}, 11^{\text {th }}$ and $12^{\text {th }}$ classes. Majority of adolescents live in nuclear family followed by $10 \%$ of them living in joint family.

According to religion, the highest percentage of them belongs to Sikh religion followed by $0 \%$ from Muslim religion.

As per number of siblings, $40.0 \%$ of adolescents were having one sibling and $1.7 \%$ of them were only child. About $100 \%$ of adolescents belong to rural area and none of them was from urban area.

As per occupation, majority ( $88.3 \%$ ) of adolescents mother were self-employed, $11.7 \%$ of them were employed, and no one from them was unemployed. As per occupation of father, $53 \%$ were employed, $46 \%$ of them were self-employed, and no one from them was unemployed.

Around $60 \%$ of adolescents mothers were having primary education followed by $40 \%$ of them were having secondary education and no one among them was graduate and postgraduate. Around $73.3 \%$ of adolescents father was having secondary education followed by $26.7 \%$ of them were having primary education and no one among them was graduate and postgraduate.

With regard to source of internet access, $100 \%$ of adolescents were having internet access through mobile phone/tablet/I pad and no one among them was having internet access through personal computer and cyber.

Table 2 describe the frequency and percentage of the level of internet addiction among adolescents. Results show that 55.0\%
Table 1: Frequency and percentage distribution of sample characteristics $(n=60)$

\begin{tabular}{|c|c|c|}
\hline Sociodemographic variables & Frequency & Percentage \\
\hline \multicolumn{3}{|l|}{ Age (in years) } \\
\hline 14 & 10 & 16.7 \\
\hline 15 & 17 & 28.3 \\
\hline 16 & 14 & 23.3 \\
\hline 17 & 5 & 8.3 \\
\hline 18 & 14 & 23.3 \\
\hline \multicolumn{3}{|l|}{ Gender } \\
\hline Male & 42 & 70.0 \\
\hline Female & 18 & 30.0 \\
\hline \multicolumn{3}{|l|}{ Class } \\
\hline $10^{\text {th }}$ & 20 & 33.3 \\
\hline $11^{\text {th }}$ & 20 & 33.3 \\
\hline $12^{\text {th }}$ & 20 & 33.3 \\
\hline \multicolumn{3}{|l|}{ Type of family } \\
\hline Nuclear & 54 & 90.0 \\
\hline Joint & 6 & 10.0 \\
\hline \multicolumn{3}{|l|}{ Religion } \\
\hline Hindu & 9 & 15.0 \\
\hline Muslim & 0 & 0 \\
\hline Sikh & 45 & 75.0 \\
\hline Others & 6 & 10.0 \\
\hline \multicolumn{3}{|l|}{ Number of siblings } \\
\hline Only child & 1 & 1.7 \\
\hline One & 24 & 40.0 \\
\hline Two & 22 & 36.7 \\
\hline Three or more & 13 & 21.7 \\
\hline \multicolumn{3}{|l|}{ Place of residency } \\
\hline Rural & 60 & 100 \\
\hline Urban & 0 & 0 \\
\hline \multicolumn{3}{|l|}{ Occupation of mother } \\
\hline Employed & 7 & 11.7 \\
\hline Self-employed & 53 & 88.3 \\
\hline Unemployed & 0 & 0 \\
\hline \multicolumn{3}{|l|}{ Occupation of father } \\
\hline Employed & 32 & 53 \\
\hline Self-employed & 28 & 46 \\
\hline Unemployed & 0 & 0 \\
\hline \multicolumn{3}{|l|}{ Education of mother } \\
\hline Primary education & 36 & 60.0 \\
\hline Secondary education & 24 & 40.0 \\
\hline Graduate & 0 & 0 \\
\hline Postgraduate & 0 & 0 \\
\hline \multicolumn{3}{|l|}{ Education of father } \\
\hline Primary education & 16 & 26.7 \\
\hline Secondary education & 44 & 73.3 \\
\hline Graduate & 0 & 0 \\
\hline Postgraduate & 0 & 0 \\
\hline \multicolumn{3}{|l|}{ Mode of internet access } \\
\hline Mobile/tablet/I pad & 60 & 100 \\
\hline Personal computer & 0 & 0 \\
\hline Cyber & 0 & 0 \\
\hline
\end{tabular}

of adolescents were having moderate internet addiction, $21.7 \%$ of adolescents were having mild internet addiction, $16.7 \%$ of them were normal users, and only $6.7 \%$ of them were having severe internet addiction.

Table 3 depicts the association of internet addiction with sociodemographic variables. Chi-square value between the level of internet addiction and sociodemographic variables including age, gender, class, number of siblings, type of family, place of residence, and mode of internet access was found to be statistically non-significant. Chi-square value between the level 
Table 2: Frequency and percentage of level of internet addiction among adolescents $(n=60)$

\begin{tabular}{lccc}
\hline Level of scoring & Frequency & Percentage & Mean and SD \\
\hline Normal range (0-30) & 10 & 16.7 & 23.75 .314 \\
Mild internet addiction & 13 & 21.7 & 47.38 \\
(31-49) & & & 0.87 \\
Moderate internet & 33 & 55.0 & 56.45 \\
addiction (50-79) & & & 5.794 \\
Severe internet addiction & 4 & 6.7 & 84.5 \\
$(80-100)$ & & & 1.915 \\
\hline
\end{tabular}

of internet addiction and sociodemographic variables including occupation of mother with $P=0.001$, occupation of father with $P=0.780$, education of mother with $P=0.052$, and education of father with $P=0.003$ was found to be statistically significant at the level of 0.05 . As calculated Chi-square value is more than the tabulated value, we accept the research hypothesis. This reveals that there was a significant association between the level of internet addiction with occupation of mother and father as well as education of mother and father.

Table 3: To find out association between internet addiction among adolescents and their selected sociodemographic variables $(n=60)$

\begin{tabular}{|c|c|c|c|c|c|}
\hline \multirow[t]{2}{*}{ Sociodemographic variables } & \multirow[t]{2}{*}{ Normal addiction } & \multicolumn{3}{|c|}{ Internet addiction } & \multirow{2}{*}{$\begin{array}{c}\chi^{2} \\
P \text { value } D\end{array}$} \\
\hline & & Mild addiction & Moderate addiction & Severe addiction & \\
\hline \multicolumn{6}{|l|}{ Age (years) } \\
\hline 14 & 3 & 1 & 6 & 0 & 13.549 \\
\hline 15 & 3 & 6 & 7 & 1 & 0.33 \\
\hline 16 & 2 & 2 & 10 & 0 & $12^{(\mathrm{NS})}$ \\
\hline 17 & 1 & 2 & 2 & 0 & \\
\hline 18 & 1 & 2 & 8 & 3 & \\
\hline \multicolumn{6}{|l|}{ Gender } \\
\hline Male & 6 & 6 & 25 & 4 & 4.327 \\
\hline Female & 4 & 6 & 8 & 0 & $\begin{array}{c}0.228 \\
3^{\text {(NS) }}\end{array}$ \\
\hline \multicolumn{6}{|l|}{ Class } \\
\hline $10^{\text {th }}$ & 4 & 6 & 10 & 0 & 9.822 \\
\hline $11^{\text {th }}$ & 3 & 4 & 13 & 0 & 0.132 \\
\hline $12^{\text {th }}$ & 3 & 3 & 10 & 4 & 6 \\
\hline \multicolumn{6}{|l|}{ Type of family } \\
\hline Nuclear & 10 & 11 & 29 & 4 & 0.544 \\
\hline Joint & 0 & 2 & 4 & 0 & $\begin{array}{c}0.132^{(\mathrm{NS})} \\
3\end{array}$ \\
\hline \multicolumn{6}{|l|}{ Religion } \\
\hline Hindu & 2 & 3 & 4 & 0 & 2.665 \\
\hline Muslim & 0 & 0 & 0 & 0 & $0.132^{(\mathrm{NS})}$ \\
\hline Sikh & 7 & 9 & 26 & 3 & 3 \\
\hline Others & 1 & 1 & 3 & 1 & \\
\hline \multicolumn{6}{|l|}{ Number of siblings } \\
\hline Only child & 1 & 0 & 0 & 0 & 6.292 \\
\hline One & 3 & 5 & 14 & 2 & $0.710^{(\mathrm{NS})}$ \\
\hline Two & 3 & 5 & 13 & 1 & 9 \\
\hline Three or more & 3 & 3 & 6 & 1 & \\
\hline \multicolumn{6}{|l|}{ Place of residency } \\
\hline Rural & 10 & 13 & 33 & 4 & - \\
\hline Urban & 0 & 0 & 0 & 0 & \\
\hline \multicolumn{6}{|l|}{ Occupation of mother } \\
\hline Employed & 1 & 0 & 3 & 3 & 17.525 \\
\hline Self-employed & 9 & 13 & 30 & 1 & $0.001^{\mathrm{s}}$ \\
\hline Unemployed & 0 & 0 & 0 & 0 & 3 \\
\hline \multicolumn{6}{|l|}{ Occupation of father } \\
\hline Employed & 5 & 6 & 18 & 3 & 1.088 \\
\hline Self-employed & 5 & 7 & 15 & 1 & $0.780^{(\mathrm{s})}$ \\
\hline Unemployed & 0 & 0 & 0 & 0 & 3 \\
\hline \multicolumn{6}{|l|}{ Education of mother } \\
\hline Primary education & 5 & 8 & 23 & 0 & 7.722 \\
\hline Secondary education & 5 & 5 & 10 & 4 & $0.052^{(\mathrm{s})}$ \\
\hline Graduate & 0 & 0 & 0 & 0 & 3 \\
\hline Postgraduate & 0 & 0 & 0 & 0 & \\
\hline \multicolumn{6}{|l|}{ Education of father } \\
\hline Primary education & 5 & 3 & 4 & 4 & 17.44 \\
\hline Secondary education & 5 & 10 & 29 & 0 & $0.003^{(\mathrm{s})}$ \\
\hline Graduate & 0 & 0 & 0 & 0 & 3 \\
\hline Postgraduate & 0 & 0 & 0 & 0 & \\
\hline \multicolumn{6}{|l|}{ Mode of internet access } \\
\hline Mobile/tablet/I Pad & 10 & 13 & 33 & 4 & - \\
\hline Personal computer & 0 & 0 & 0 & 0 & \\
\hline Cyber & 0 & 0 & 0 & 0 & \\
\hline
\end{tabular}




\section{Discussion}

The results of the present study depicts that $55.0 \%$ of adolescents were having moderate internet addiction, $21.7 \%$ of adolescents were having mild internet addiction, $16.7 \%$ of them were normal users, and only $6.7 \%$ of them were having severe internet addiction.

A similar cross-sectional study was conducted on internet addiction among adolescents from private school of Haridwar, Uttarakhand. A cross-sectional survey design was used for 52 randomly selected adolescents. More than half (53.8\%) of the participants had moderate internet addiction and 7.7\% had severe internet addiction which could possibly affect the physical and mental health of the youngsters. ${ }^{[9]}$

The results of findings depict that the Chi-square value between the level of internet addiction and sociodemographic variables including occupation of mother with $P=0.001$, occupation of father with $P=0.780$, education of mother with $P=0.052$, and education of father with $P=0.003$ was found to be statistically significant at the level of 0.05 . This reveals that there was a significant association between the level of internet addiction with occupation of mother and father as well as education of mother and father.

It is contradicted by a descriptive study done to assess the level of internet addiction among adolescents: A case study of high schools in Mangalore. The tool consisted of a baseline pro forma, a modified form of IA test and a structured questionnaire developed during the study. The study revealed that majority (70.5\%) of the adolescents were normal users, $23 \%$ had a mild addiction, $6 \%$ had a moderate addiction, and $0.5 \%$ had a severe addiction. The majority (73\%) of samples had a mild impact, $16.5 \%$ had a moderate impact, and $10.5 \%$ had no impact. There was a significant association between impact due to IA with some of their selected demographic variables, namely, gender, age, class, presently residing, and occupation of father of the high schools students and the null hypothesis $\left(\mathrm{H}_{03}\right)$ was rejected. ${ }^{[4]}$

A comparative study was conducted among children $(n=70)$ of two district between Sagar (Madhya Pradesh) and Surajpur (Chhattisgarh), India, to assess the pattern of internet addiction. Researcher has employed semi-structured interview schedule to collect primary data it's includes like socioeconomic profiles of the respondent with Young's Internet Addiction Test scale (IAT) with translated into Hindi language and the participants age between 7 and 18 years old. According to Young's 20 -item scale, $9(12.85 \%)$ respondents (score $>79$ ) were severe addicts of internet, and most important these all are belonging from Sagar. Thirty-nine $(55.72 \%)$ respondents as moderate (score $50-79)$ and $22(31.43 \%)$ respondents were mild and safe $($ score $<49) .{ }^{[10]}$

\section{Conclusion}

The present study revealed that majority of the adolescents were having moderate internet addiction and there was a significant association between the level of internet addiction with occupation and education of parents.

\section{RefERENCES}

1. Rudan V, Klein E. Internet addiction through the phase of adoloscence. JMIR Ment Health 2017;4:212-22.

2. Pernar M. Internet addiction through the phase of adolescence: A questionnaire study. JMIR Ment Health 2017;4:11.

3. Young K. Internet addiction: Evaluation and treatment. Stud Br Med J 1999;7:351-2.

4. Achenbach TM, Becker A, Döpfner M, Heiervang E, Roessner V, Steinhausen $\mathrm{H}$, et al. Multicultural assessment of child and adolescent psychopathology with ASEBA and SDQ instruments. J Child Psychol Psychiatry 2008;49:251-75.

5. Graovac M. Adolescent in family. Med Fluminensis 2010;46:261-6.

6. Zboralski K, Orzechowska A, Talarowska M, Darmosz A, Janiak A, Janiak M, et al. The prevalence of computer and Internet addiction among pupils. Postepy Hig Med Dosw 2009;63:8-12.

7. Kyastha B, Gurung A, Chawal R. A descriptive study to assess internet addiction among adolosents. J Child Adolesc Behav 2018;6:378.

8. Byun S, Ruffini C, Mills JE, Douglas AC, Niang M, Stepchenkova S, et al. Internet addiction: Meta synthesis of 1996-2006 quantitative research. Cyber Psychol Behav 2008;12:1-5.

9. Chauhan V, Kaur BN, Singh R. Internet addiction among adolosents. Int J Trend Sci Res Dev 2017;6: April 2020.

10. Kumar R, Mahendra SK, Rajput D. Internet addiction: A comparative study among children in the State of Madhya Pradesh and Chhattisgarh. Int J Res Anal Rev 2018;5:950-8.

How to cite this article: Bajwa RK, Maheshwari SK. A Study to Assess the Internet Addiction among Adolescents Studying in Dyal Singh Government Senior Secondary School, Mirjajan, District Gurdaspur, Punjab. Int J Nurs Med Invest. 2020;5(2):15-19 